http://dx.doi.org/10.1590/0102-311XCO06S114

Maria A. S. Mendes Gomes

Instituto Nacional de Saúde da Mulher da Criança e do Adolescente Fernandes Figueira, Fundação Oswaldo Cruz, Rio de Janeiro, Brasil. mariasmsdc@gmail.com

\section{Commitment to change}

The concern with birth in Brazil is not new. Since the 1990s, the Brazilian Ministry of Health has sought to ensure good obstetric and neonatal practices, and a proper environment for what should be a moment of celebration and joy. The Stork Network (launched in 2011 as one of the five primary health policies in Brazil) reinforced such commitment, and stressed the urgency in reviewing care processes in Brazilian maternity facilities.

However, from a national perspective, the analysis of perinatal indicators, and the experiences undergone by Brazilian women indicate the existence of a challenging scenario. This was the scenario a group of investigators lead by Prof. Maria do Carmo Leal looked into, with the research Birth in Brazil. Managers, researchers, health practitioners, and social movements had in their hands an unprecedented and weighty study that documents the medically and physiologically unexplainable care practices of childbirth processes.

I contribute to this discussion by sharing the same unease shown by the authors, who highlight the difficulties in the interpretation of Brazilian data, and the opposing care-delivery processes in their different variables (region of the country, access to private health-care networks, years of schooling, ethnicity/skin color, and type of birth delivery). It is within this perspective of contradiction that I present my stand: despite the current scenario, we experience a fertile and promising time for reviewing ideas, values and, therefore, care-delivery practices.

This moment we are experiencing now can be characterized by a set of situations and elements capable of synergistic action to effectively change birthcare and delivery in Brazil. In this process, I highlight: (1) a considerable increase in the number of studies on care deficiencies and institutional abuse; (2) sustainable experiences of good public perinatal practices developed in cities such as Belo Horizonte (Minas Gerais State) and Rio de Janeiro, which included reviewing of routines and monitoring process and outcome indicators, environmental interventions, and of the role of obstetric nursing in habitual-risk births; (3) focus of federal government actions considered a priority for maternity facilities of the Northern and Northeastern regions, through the Maternities Qualification Plan; (4) consolidation of the National Humanization Policy as the driving force in health-provision networks, 
which ensures institutional support for the development of best practices; (5) expansion of obstetric nursing training, making more practitioners available and skilled in the management of habitual-risk births; (6) appreciation by strategic players in Brazilian obstetrics of evidence-based medical practice to replace the repetition of unnecessary or harmful practices to habitual-risk the delivery and birth; (7) strong and increasing dissatisfaction of women with their experience in public and private maternities.

These are movements that occur with different hues, and social and regional differences, but that bear the same importance. Studies on care deficiencies and institutional abuse in maternities have strengthened social movements and are fostering discussions and action in bodies such as the Public Ministry and Legislatures.

The experiences in capital cities of the Northeastern region reinforce the analysis of the authors about higher adhesion to good practices in this area, which is known for its important role in the countrywide dissemination of knowledge and practices. Similarly, the characteristics of the development of the Stork Network (attention to "how to do", and provision of institutional support to less developed areas) evidence that its purpose goes beyond the expansion of the existing capacity; otherwise there would be "more of the same".

Even though still incipient countrywide, the growing role of obstetric nursing, due to its positive impact in the improvement of outcomes ${ }^{1}$, is decisive to change the way birth occurs in Brazil. The experiences of more than a decade in maternities and birthcare facilities managed by the local government in the cities of Rio de Janeiro and Belo Horizonte have become important sites for development of knowledge and systematization of practices. Since 2012, a number of initiatives involving the federal government, universities and nursing organizations are in place, to intensify professional training under different modalities (residency, continuing education, refresher courses), for practitioners to work in maternities throughout the country.

The valuation of "evidence-based obstetrics", recognized and accepted worldwide, as well as its positive influence in the training of new generations of obstetricians, has been seen in maternities that present indicators closer to the ones of countries with the best perinatal indices. Some of these practitioners, since their training, are exposed to institutional environments in which, from the physical structure of the facilities to the established routines (including the role of obstetric nursing 1), favor the physiology of the habitual-risk delivery.
The dissatisfaction with institutional routines with little focus on the woman and her family is increasing gradually, with the rising awareness of rights within Brazilian society. In the public care facilities, the right to have a companion present serves as an important example, and it is becoming irreversible countrywide. On the other hand, women who use the private sector are very incisive in claiming their right to normal vaginal delivery. As odd as this may sound in countries such as England, France or Canada, Brazil presents c-section delivery rates close to $90 \%$ in the private sector, which makes the claim easier to understand. A number of testimonies of users and doctors of the private sector mention elements foreign to the medical process to account for performing a c-section. This seems to me an irreversible movement, and its connection to the Brazilian film O Renascimento do Parto ("The Revival of Delivery"), shown in paid movie theaters, is an encouraging sign of such a process.

From these thoughts and my confidence in the possibilities of change, I share with the authors and readers my certainty about the long path ahead of us. Among the many and complex issues that require a lot of thinking, there are three that I believe are the core ones: (1) rediscussion and re-arrangement of perinatal care processes in university hospitals. The limited role of obstetric nursing at the scene of delivery in these institutions that are known to be opinionmakers, hampers and delays in the academic setting, the revision of medical practices and routines, research, knowledge production, and the ongoing training and education of the different professional categories; (2) just like the authors, I highlight the prenatal care provided by the public health network as an instrumental agent for women to be given much of the ownership in regards to the physiology and importance of normal vaginal delivery, deconstructing the commonly perceived negative experiences often disseminated in our milieu; (3) revision of the processes in the production of care in the private sector, lessening the impact of external factors to the medical care when deciding on the type of delivery.

I end by mentioning and appreciating the role of an organization that is thoroughly strategic for the necessary and urgent revisions in obstetric care in Brazil. In a recent and historical stand on delivery and habitual-risk birth, the Brazilian Federation of Gynecology and Obstetrics (FEBRASGO. http://www.febrasgo.org.br/ site/?p=7069, accessed on 29/Jan/2014) advocates practices known to increase the satisfaction of pregnant women with vaginal delivery (diet, privacy, comfort, walking-capacity, relaxation, 
freedom for selecting position in the second stage, limited use of episiotomy), supports intrahospital, dystocia-free birthcare centers, the role of obstetric nursing in public and private clinics, and the creation of on-call teams to provide normal vaginal delivery care in HMO-managed facilities. This is a stand that reinforces my confidence of a new era for those who are born in Brazil.

1. Sandall J, Soltani H, Gates S, Shennan A, Devane D. Midwife-led continuity models versus other models of care for childbearing women. Cochrane Database Syst Rev 2013; 8:CD004667. 